\title{
Human NK Cell Development: One Road or Many?
}

\author{
Frank Cichocki ${ }^{1 *}$, Bartosz Grzywacz ${ }^{2}$ and Jeffrey S. Miller ${ }^{1}$ \\ ${ }^{1}$ Department of Medicine, University of Minnesota, Minneapolis, MN, United States, ${ }^{2}$ Department of Laboratory Medicine \\ and Pathology, University of Minnesota, Minneapolis, MN, United States
}

$\mathrm{CD}^{-}{ }^{-} \mathrm{CD} 56^{+} \mathrm{NK}$ cells develop from CD34+ hematopoietic progenitors (HPCs) in vivo, and this process can be recapitulated in vitro. The prevailing model is that human NK cell development occurs along a continuum whereby common lymphocyte progenitors (CLPS) gradually downregulate CD34 and upregulate CD56. Acquisition of CD94 marks commitment to the CD56 bright stage, and CD56 bright $\mathrm{NK}$ cells subsequently differentiate into CD56 dim NK cells that upregulate CD16 and killer immunoglobulin-like receptors (KIR). Support for this linear model comes from analyses of cell populations in secondary lymphoid tissues and in vitro studies of NK cell development from HPCs. However, several lines of evidence challenge this linear model and suggest a more branched model whereby different precursor populations may independently develop into distinct subsets

OPEN ACCESS

Edited by:

Aharon Freud

The Ohio State University,

United States

Reviewed by:

Steven Scoville,

The Ohio State University,

United States

Karl-Johan Malmberg,

Oslo University Hospital, Norway

*Correspondence: Frank Cichock

cich0040@umn.edu

Specialty section:

This article was submitted to NK and Innate Lymphoid Cell Biology,

a section of the journal

Frontiers in Immunology

Received: 21 June 2019 Accepted: 16 August 2019

Published: 29 August 2019

Citation:

Cichocki F, Grzywacz B and Miller JS (2019) Human NK Cell Development:

One Road or Many?

Front. Immunol. 10:2078.

doi: 10.3389/fimmu.2019.02078 of mature NK cells. A more definitive understanding of human NK cell development is needed to inform in vitro differentiation strategies designed to generate NK cells for immunotherapy. In this review, we summarize current evidence supporting the linear and branched models of human NK cell development and the challenges associated with reaching definitive conclusions.

Keywords: NK cell, development, precursor, innate, adaptive, progenitor, immune, differentiation

\section{THE PLASTICITY OF EARLY HUMAN HEMATOPOIESIS}

The population of cells comprising human blood is organized as a cellular hierarchy derived from multipotent stem cells. The first in vivo experiments demonstrating reconstitution of the hematopoietic system from stem cells were based on rescue of lethal irradiation by bone marrow transplant in mice (1). Subsequent bone marrow transplant experiments in mice provided estimates of the minimal number of hematopoietic stem cells (HSCs) that could reconstitute hematopoiesis (2) and revealed in vivo proof for the multipotent nature of stem cells (3). The advent of flow cytometry and cell sorting allowed for purification of hematopoietic stem cells and demonstration that a small number of these cells could reconstitute all blood cell types in lethally irradiated mice (4).

Throughout the past two decades there have been numerous studies characterizing hematopoietic stem cells and determinants of self-renewal or differentiation. In early models of the hematopoietic differentiation tree, the first branch point segregated common lymphoid progenitor cells (CLPs) from common myeloid progenitors (CMPs). Subsequent modifications to the tree have been made based on work showing that the HSC pool is very heterogeneous in terms of self-renewal and differentiation properties. One landmark discovery that challenged the standard branched tree paradigm of human hematopoiesis was the identification of a population of multi-lymphoid progenitor cells (MLPs) that could generate all lymphoid cell types, as well as 
monocytes, macrophages, and dendritic cells (DCs). MLPs were characterized as a distinct Thy- $1^{\text {neg-low }} \mathrm{CD} 45 \mathrm{RA}^{+}$population within the $\mathrm{CD} 34^{+} \mathrm{CD} 38^{-}$HSC pool of both cord blood and bone marrow. When cultured on the MS-5 murine stromal cell line, MLPs differentiated into myeloid cells, B cells, and NK cells at a nearly 1:1:1 ratio. A large fraction of MLPs could also differentiate into T cells when cultured on OP9 murine stromal cells transduced with the Notch ligand DL1 (5). This work, along with other studies showing macrophage potential in thymic progenitors, CLPs, and B cell progenitors call into question the lymphoid-restricted state of the presumed CLP (6-10) and led to a model whereby multipotential progenitors (MPPs) initially differentiate into lymphoid-primed multipotential progenitors (LMPP) (11-14) in route to definitive myeloid and lymphoid commitment $(15,16)$.

Several important conclusions can be drawn from these studies. First, there exists considerable heterogeneity and plasticity with regards to hematopoiesis and lineage potential of precursors. Second, precursors with some degree of B and $\mathrm{T}$ cell lineage restriction appear to retain NK cell and myeloid potential. From an evolutionary perspective, the innate myeloid and NK cell lineage pathways may represent ancestral programs that are retained in progenitors. Adaptive immunity, when it arose, may have been layered onto the ancestral programs, resulting in further hematopoietic lineage diversification. Third, signals within the microenvironment in which a progenitor resides provide instructive signals that strongly influence the developmental path of a given progenitor.

\section{NK CELL PRECURSORS AND ONTOGENY}

One of the first reports aimed at defining the precursor origin of NK cells was performed by Kumar and colleagues in the mid 1980's. The authors transplanted syngeneic bone marrow cells into lethally irradiated mice that were also depleted of NK cells by injection of an anti-asialo GM1 antibody. Using this system, the authors demonstrated that an intact bone marrow microenvironment was necessary for the development of mature, lytic NK cells, and that NK cell precursors lack expression of several surface antigens that define mature NK cells (17). Subsequently, an early foray into human NK cell ontogeny was undertaken by Lanier et al. who characterized freshly isolated NK cells from fetal tissue. The most striking finding from this study was that fetal NK cells, in contrast to adult peripheral blood NK cells, expressed intracellular (but not surface) CD $3 \delta$ and CD $3 \varepsilon$. This led to the hypothesis that NK cells and T cells may share a common precursor that splits to the $\mathrm{T}$ or NK cell lineage depending on environmental cues (18). Contemporaneously, Reinherz and colleagues identified a dominant fetal thymocyte population in mice lacking expression of CD4 and CD8 but expressing Fc gamma RII/III prior to TCR acquisition in vivo. If maintained in a thymic environment, these precursors exhibited stepwise differentiation into canonical $\mathrm{CD}^{+} \mathrm{T}$ cells. If removed from the thymus, these precursors developed into canonical NK cells with cytotoxic function (19). Subsequently, in vitro fetal thymic organ culture experiments using mouse fetal thymocytes demonstrated that a T/NK-committed progenitor defined as $\mathrm{NK} 1.1^{+} \mathrm{CD} 117^{+} \mathrm{CD} 44^{+} \mathrm{CD} 25^{-}$could efficiently develop into $\mathrm{T}$ cells if cultured in a thymic microenvironment, whereas coculture with bone marrow-derived stromal cells resulted in the generation of mature NK cells (20). Support for a developmental relationship between $\mathrm{NK}$ cells and $\mathrm{T}$ cells also comes from whole-genome microarray analyses of murine splenic leukocyte populations. At the transcriptome level, NK cells and T cells cluster within a complex that is distinct from those formed by subsets of B cells, DCs, and macrophages by principal components analysis (21).

Compelling evidence exists for the idea that $T$ celldetermining factors are needed to enforce the development of precursor cells into the $\mathrm{T}$ cell lineage, and the NK cell lineage becomes the default pathway in the absence of these factors. Several murine studies have shown that one of the earliest checkpoints in $\mathrm{T}$ cell development is dependent on the zincfinger transcription factor Bcl11b. Bcl11b-deficient mice exhibit impaired thymocyte development between the DN3 to immature SP stage because of an inability to rearrange the TCR $V_{\beta}$ to $D_{\beta}$ gene segments (22). Genetic deletion of Bcl11b in conditional knockout mice results in a loss of $\mathrm{T}$ cell identity in developing DN3 thymocytes and reprograming to a morphological and transcriptional state resembling that of NK cells (23-25). One interpretation of these results is that early progenitor cells with intrinsic $\mathrm{T}$ cell potential but low or absent Bcl11b expression differentiate into NK cells, providing support for the existence of a common $\mathrm{T} / \mathrm{NK}$ progenitor. Another interpretation is that Bcl11b expression is necessary to enforce $\mathrm{T}$ cell identity during development by overriding a more ancestral NK-like program, and there is no actual NK/T lineage split determined by Bcl11b. The latter interpretation seems more likely based on a report of a patient that contained a mutant BCL11B variant causing dysregulated binding of BCL11B to promoter targets. The patient exhibited a "leaky" form of severe combined immunodeficiency (SCID) and very low T cell counts. However, NK cell counts were within the normal range (26).

There has been a continuous evolution regarding our understanding of the earliest stages of progenitor cell commitment to the NK cell lineage. An updated model of human lymphopoiesis has been put forth postulating that lymphoid development stems from distinct populations of $\mathrm{CD}_{127}{ }^{-}$and $\mathrm{CD}_{127^{+}}$early lymphoid progenitors (ELPs). Evidence for this model is supported by experiments where CD34 ${ }^{+}$HSCs were engrafted into immunodeficient mice and subsequently phenotyped for surface expression of various lineage markers. Representation of flow cytometry data using tree-plots suggested that lymphoid cells differentiated along two pathways, distinguished by expression of CD127, that originates from $\mathrm{CD} 34^{\text {high }} \mathrm{CD} 45 \mathrm{RA}^{+}$progenitors. A series of in vitro differentiation assays showed that $\mathrm{CD}_{12}{ }^{-}$ELPs could generate $\mathrm{T}$ cells, marginal zone B cells, NK cells, and innate lymphoid cells (ILCs), while CD $127^{+}$ELPs could generate marginal zone B cells, NK cells, and ILCs. Molecular characterization of in vitro-generated $\mathrm{NK}$ cells identified substantial differences according to whether cells originated from $\mathrm{CD} 127^{-}$or $\mathrm{CD} 127^{+}$ NKIPs. NK cells derived from CD127 ${ }^{-}$NKIPs expressed higher 
levels of $G Z M B, I F N G$, and $G Z M K$ and secreted higher levels of IFN- $\gamma$ and TNF- $\alpha$ when stimulated with PMA. NK cells derived from $\mathrm{CD}_{127}{ }^{+} \mathrm{NKIPs}$ expressed higher levels of genes encoding several transcription factors including RUNX1, TCF4, NFIL3, MYC, LEF1, EOMES, ETS1, TCF12, and BCL11B and exhibited marginally higher degranulation in response to K562 stimulation (27). Further dissection of the relative contribution of CD127 and $\mathrm{CD} 127^{+}$NKIPs to the mature peripheral blood NK cell pool and NK cell subsets in various tissues will be of interest.

Because of the complexity and plasticity of early hematopoiesis and lineage commitment, it has been challenging to define lineage-restricted NK cell progenitors. A foundational study by Chen and colleagues showed that a subpopulation of $\mathrm{CD}_{34}{ }^{+} \mathrm{Lin}^{-} \mathrm{CD}_{45 \mathrm{RA}}{ }^{+}$cells expressing CD10 could give rise to $\mathrm{T}$ cells, $\mathrm{B}$ cells, NK cells, and DCs under supportive culture conditions (28). Similar results were reported by Miller et al. who demonstrated that $2 \%$ of bone marrow cells with a $\mathrm{CD} 34^{+} \mathrm{Lin}^{-} \mathrm{CD} 38^{-}$phenotype could give rise to at least three lineages (NK cells, B cells, and myeloid cells) under the same culture conditions (29). Subsequent work comparing lymphoid potential of $\mathrm{CD} 4^{+} \mathrm{Lin}^{-} \mathrm{CD} 45 \mathrm{RA}^{+}$cells isolated from cord blood concluded that $\mathrm{CD}_{3} 4^{+} \mathrm{Lin}^{-} \mathrm{CD} 45 \mathrm{RA}{ }^{+} \mathrm{CD} 10^{+}$ progenitors predominantly exhibited $\mathrm{B}$ cell potential, while $\mathrm{CD}^{2} 4^{+} \mathrm{Lin}^{-} \mathrm{CD}_{45 \mathrm{RA}^{+} \mathrm{CD}^{+}}{ }^{+}$progenitors skewed more toward the $\mathrm{T}$ cell and NK cell lineages when differentiated in vitro (30). Support for CD7 expression by the putative NK cell progenitor came from experiments showing a high cloning efficiency of $\mathrm{CD}^{-}{ }^{-} \mathrm{CD}_{56}{ }^{+} \mathrm{NK}$ cells from $\mathrm{CD} 34^{+} \mathrm{CD} 7^{\text {bright }}$ bone marrow progenitors (31). Another study of lymphoid and myeloid lineage commitment using precursors from cord blood described B cell and NK cell potential from $\mathrm{CD} 34^{+} \mathrm{CD} 38^{-} \mathrm{CD} 10^{+} \mathrm{CD} 7^{+}$ progenitors with barely detectable expansion of these cells in myeloid stromal cultures (32). An important step forward in identifying a lineage-restricted NK cell progenitor was made about a decade later with the identification of a very rare population of cord blood and bone marrow progenitors with a $\mathrm{Lin}^{-} \mathrm{CD}_{34}{ }^{+} \mathrm{CD} 38^{+} \mathrm{CD}_{123}{ }^{-} \mathrm{CD} 45 \mathrm{RA}^{+} \mathrm{CD}^{+}{ }^{+} \mathrm{CD} 10^{+} \mathrm{CD} 127^{-}$ phenotype that gave rise exclusively to $\mathrm{NK}$ cells when co-cultured at limiting dilutions with supporting stroma and after transplantation into newborn immune-deficient mice. These NK cell precursors were shown to be "downstream" of CLP-like cells with a $\mathrm{Lin}^{-} \mathrm{CD} 34^{+} \mathrm{CD} 38^{+} \mathrm{CD} 123^{-} \mathrm{CD} 45 \mathrm{RA}^{+} \mathrm{CD}^{+} \mathrm{CD} 10^{+} \mathrm{CD} 127^{+}$ phenotype (33). It would be of considerable interest to revisit the place of these lineage-restricted NK cell precursors in the hematopoietic hierarchy in the context of the "two-family" model, which posits that $\mathrm{CD}_{12}{ }^{-}$and $\mathrm{CD} 127^{+}$ELPs differentiate independently and can each give rise to NK cells (27).

Another population of lineage-restricted progenitor cells with NK and $\mathrm{T}$ cell potential characterized as $\mathrm{Lin}^{-} \mathrm{CD} 34^{+} \mathrm{DNAM}-$ $1^{\text {bright }}{ }^{2 X C R} 4^{+}$has been described. These cells were bonemarrow-resident, but increased markedly in circulation in individuals with chronic infections. Ex vivo culture of these cells with cytokines (FLT3, SCF, IL-7, IL-15) led to the development of NK cells and TCR $\alpha / \beta^{+} \mathrm{T}$ cells, but not myeloid cells. In contrast, cord blood-derived $\mathrm{CD} 34^{+} \mathrm{DNAM}^{-} \mathrm{CXCR} 4^{-}$ progenitor cells in the same culture conditions gave rise to
NK and myeloid cells (34). Where these $\mathrm{Lin}^{-} \mathrm{CD} 34^{+}$DNAM$1^{\text {bright }} \mathrm{CXCR} 4^{+}$progenitor cells fit within the developmental hierarchy of $\mathrm{NK}$ cells is unclear. It will be of interest to determine whether cytotoxic lymphocytes that arise from these unique progenitors play an important role in the anti-viral immune response.

\section{THE LINEAR MODEL OF NK CELL DEVELOPMENT}

$\mathrm{CD}^{-}{ }^{-} \mathrm{CD} 56^{+} \mathrm{NK}$ cells with cytotoxic function can be generated in vitro after long-term culture of $\mathrm{CD}_{3}{ }^{+}$cells isolated from cord blood, bone marrow, fetal liver, thymus, or secondary lymphoid tissue with IL-2 or IL-15 (31, 35-38). Based on the anatomical locations of progenitors and their capacity to develop into NK cells under supportive conditions, a stepwise model for development and maturation of human NK cells has been put forth by Freud and Caliguiri. In this model, HSCs give rise to "Stage 1" progenitors that retain CD34 expression and acquire CD45RA and CD10. These cells give rise to "Stage 2" progenitors marked by loss of CD10 expression and acquisition of CD117. "Stage 3" is marked by downregulation of CD34 and acquisition of LFA-1. These cells are presumed to be restricted to the NK cell lineage given their inability to differentiate into $\mathrm{T}$ cells or DCs in vitro and their capacity for efficient differentiation into bona fide NK cells in response to IL-15. "Stage 4" is marked by acquisition of CD94, and these cells represent the CD56 bright NK cell subset. The precursor population for CD56 $6^{\text {bright }}$ cells has been identified as exhibiting a CD34 ${ }^{\text {dim }} \mathrm{CD} 45 \mathrm{RA}^{+}$integrin $\alpha_{4} \beta_{7}$ phenotype (38). Further differentiation into "Stage 5 " cells is marked by downregulation of CD94 and acquisition of CD16 and killer immunoglobulin-like receptors (KIR). These cells represent the CD56 ${ }^{\text {dim }}$ NK cell subset (39).

The presumed developmental transition from a CD56 bright to a CD56 ${ }^{\mathrm{dim}}$ phenotype is perhaps the most controversial step in this developmental model. A good case can be made for this developmental pathway. CD56 ${ }^{\text {bright }} \mathrm{NK}$ cells are the predominant population early after hematopoietic cell transplant. Their frequency decreases by 3 months posttransplant, concomitant with an increase in the percentage of CD56 ${ }^{\mathrm{dim}} \mathrm{NK}$ cells (40). While this pattern of $\mathrm{NK}$ cell reconstitution could reflect a developmental relationship, an alternative hypothesis is that the abundance of CD56 $6^{\text {bright }} \mathrm{NK}$ cells early post-transplant is due to high levels of homeostatic expansion of this subset in the setting of lymphopenia induced by transplant conditioning. Additional support for a developmental relationship between CD56 $6^{\text {bright }}$ and CD56 ${ }^{\text {dim }} \mathrm{NK}$ cells comes from the identification of a functionally and phenotypically intermediate population of CD $56^{\mathrm{dim}} \mathrm{CD} 94^{\text {high }} \mathrm{NK}$ cells that have been described as a transitional population between $\mathrm{CD} 56^{\text {bright }}$ and CD56 ${ }^{\mathrm{dim}} \mathrm{CD} 94^{\text {low }} \mathrm{NK}$ cells (41). However, whether human NK cells differentiate from CD56 bright to CD56 ${ }^{\text {dim }}$ CD $94^{\text {high }}$ to $\mathrm{CD} 56^{\mathrm{dim}} \mathrm{CD} 94^{\text {low }}$ has not been definitively established. Interestingly, CD94 has also been used as a marker to define phenotypically and functionally distinct NK cell subsets in mice. Murine CD94 $4^{\text {high }}$ NK cells share phenotypic and functional 
properties with human $\mathrm{CD} 56^{\mathrm{dim}} \mathrm{CD} 94^{\text {high }}$ NK cells. When CD94 ${ }^{\text {high }}$ and $\mathrm{CD} 94^{\text {low }} \mathrm{NK}$ cells were purified and adoptively transferred into congenic mice, CD94 ${ }^{\text {low }}$ NK cells became CD94 $4^{\text {high }}$ but not vice versa (42).

Perhaps the strongest evidence in support of the idea that $\mathrm{CD} 56^{\text {bright }} \mathrm{NK}$ cells differentiate into CD56 ${ }^{\mathrm{dim}} \mathrm{NK}$ cells comes from studies where CD56 $6^{\text {bright }} \mathrm{NK}$ cells were sorted and stimulated in vitro. In a study by Chan et al., a fraction of sorted CD56 bright $\mathrm{NK}$ cells co-cultured with synovial fibroblasts exhibited CD56 downregulation and had a phenotype consistent with $\mathrm{CD} 56^{\mathrm{dim}} \mathrm{NK}$ cells. The apparent differentiation of CD56 ${ }^{\text {bright }} \mathrm{NK}$ cells to CD $56^{\text {dim }} \mathrm{NK}$ cells could be inhibited by the addition of an antibody that blocks fibroblast growth factor receptor 1 (FGFR1). Of note, stimulation of CD56 $6^{\text {bright }} \mathrm{NK}$ cells with a combination of IL-2, IL-15, and 721.221 cells did not induce differentiation to a CD56 $6^{\mathrm{dim}}$ phenotype. CD56 $6^{\text {bright }} \mathrm{NK}$ cells that were adoptively transferred into NOD-SCID mice were almost uniformly $\mathrm{CD} 56^{\mathrm{dim}} \mathrm{CD} 16^{+}$when analyzed 10 days later in the blood, spleen, and lymph nodes. Furthermore, CD56 ${ }^{\text {bright }} \mathrm{NK}$ cells were shown to have longer telomere repeat lengths relative to $\mathrm{CD} 56^{\mathrm{dim}} \mathrm{NK}$ cells, suggesting that they are more naïve (43). A contemporaneous study by Romagnani et al. reported on the acquisition of $\mathrm{CD} 56^{\mathrm{dim}} \mathrm{NK}$ cell features such as KIR and CD16 upregulation after stimulation of sorted CD56 $6^{\text {bright }} \mathrm{NK}$ cells with IL-2 or IL-15 and confirmed the existence of longer telomere repeats in CD56 $6^{\text {bright }} \mathrm{NK}$ cells (44). The discrepancies between these two studies with respect to the role of cytokines in driving maturation of CD56 $6^{\text {bright }} \mathrm{NK}$ cells may be due to experimental techniques, but additional studies are needed to gain a more definitive understanding of this stage of NK cell maturation. Indeed, it's somewhat surprising that no follow up studies looking deeper into the FGF signaling pathway and its role in driving NK cell maturation have been published.

The CD56 $6^{\mathrm{dim}} \mathrm{NK}$ cell subset in peripheral blood is heterogeneous mix of cells with respect to the expression of KIR, CD94, NKG2A, CD62L, and CD57. Relative surface expression levels of these molecules are indicative of maturation status. The current model based on analysis of peripheral blood NK cells from healthy donors and NK cell reconstitution after hematopoietic cell transplantation suggests that as CD56 ${ }^{\mathrm{dim}}$ NK cell mature, they downregulate NKG2A and CD62L and subsequently acquire KIR and CD57. Sequential maturation is associated with a gradual decline in proliferative capacity in response to IL-2 or IL-15 $(45,46)$. The acquisition of inhibitory KIR and NKG2A after lineage commitment has been studied using in vitro models of human NK cell development from $\mathrm{CD} 34^{+}$precursors $(47,48)$. However, late stage NK cell differentiation and maturation is difficult to study using current culture conditions. NK cell development from CD34 precursors in vitro is a slow process that takes $\sim 4$ weeks, and $\mathrm{CD}^{-}{ }^{-} \mathrm{CD} 56^{+}$ NK cells generally exhibit low-to-absent expression of KIR, $\mathrm{CD} 16$, and CD57. Additionally, signaling through the common $\gamma$-chain cytokines IL-2 and IL-15 drives high expression of CD56, NKG2A, and cytotoxic granule components in cultured NK cells. Thus, innovative new approaches need to be developed in order to study the paths of late stage NK cell maturation and the mechanisms that influence NK cell heterogeneity.

\section{EVIDENCE FOR A NON-LINEAR MODEL OF NK CELL DEVELOPMENT}

The linear model of human NK cell development is a useful construction. Within it lie some fundamental truths, such as the concept that multipotent progenitor cells become lineage restricted and further mature. However, we may need to go beyond this model to understand NK cell heterogeneity. NK cells were once thought to be a relatively homogenous lymphocyte population, particularly in comparison to $\mathrm{T}$ and $\mathrm{B}$ cells that can generate remarkable receptor diversity through somatic DNA recombination. This view has changed with the advent of more sophisticated technologies for cellular analysis and computing power. Using mass cytometry with a panel of 28 NK cell receptors, Horowitz et al. phenotyped peripheral blood NK cells from five sets of monozygotic twins and 12 unrelated donors with defined KIR and HLA genotypes. Using a Boolean gating strategy to analyze the mass cytometry data, they estimated 6,000-30,000 phenotypic populations within an individual and more than 100,000 phenotypes in the entire donor panel. Interestingly, no single phenotype accounted for more than $7 \%$ of the total NK cells, and subsets comprising the top 50 phenotypes accounted for an average of only $15 \%$ of a given individual's NK cells. Hierarchical clustering of NK cell populations on the basis of surface receptors showed that the major distinguishing receptors were CD94, NKG2A, CD16, and CD57. Two separate clusters emerged: a less mature $\mathrm{CD} 94^{+} \mathrm{NKG} 2 \mathrm{~A}^{+}$cluster and a mature $\mathrm{CD} 16^{+} \mathrm{CD} 57^{+}$cluster (49). With the existence of these new technologies and sophisticated methods of analysis, it will be exciting to find out how population frequencies shift in the context of aging and disease. It will also be of interest to know whether less mature populations such as the $\mathrm{CD} 94^{+} \mathrm{NKG} 2 \mathrm{~A}^{+}$ population continually mature and alter their phenotype or whether they are more static and fixed at their stage of differentiation. It is currently unknown whether the astounding diversity found within the peripheral blood NK cell population is largely a reflection of a spectrum of maturational states and stochastic receptor expression influenced by the environment or whether clonal diversity within the precursor pool dictates NK cell phenotypes. In this section we review evidence for the hypothesis that NK cell diversity could be determined at the precursor level.

The idea that NK cells develop exclusively from CLPs was challenged by experiments showing that CMPs and granulocyticmonocytic precursors (GMPs) isolated from cord blood could efficiently differentiate into NK cells when cultured in the presence of NK-supporting cytokines and stroma. Additionally, NK cells derived from myeloid precursors variably expressed colony-stimulating factor receptor (CSFR) during culture. Both $\mathrm{CSFR}^{-}$and $\mathrm{CSFR}^{+}$progenitors gave rise to functional $\mathrm{CD} 56^{+}$ NK cells if cultured in NK-supporting conditions, and addition of colony-stimulating factor (CSF) to NK cell cultures skewed development toward the monocyte lineage in a dose-dependent manner. Interestingly, NK cells derived from $\mathrm{CSFR}^{+}$myeloid precursors exhibited significantly higher killer immunoglobulinlike receptor (KIR) expression (50). More KIR acquisition on NK cells derived from myeloid precursors could be related 
to CSFR, which signals through the transcription factor Myc (51). Upstream distal KIR promoters have binding sites for $\mathrm{Myc}$, and Myc overexpression drives KIR gene transcription (52). Importantly, a fraction of NK cells with a more mature NKG2 $\mathrm{A}^{-} \mathrm{KIR}^{+}$phenotype was identified in cultures where NK cells were derived from $\mathrm{CSFR}^{+}$progenitors, and this population was absent in cultures where NK cells were derived from $\mathrm{CSFR}^{-}$progenitors (50). Supporting evidence for human NK cell differentiation from myeloid progenitors was reported in a more recent study of NK cell reconstitution in humanized mice. In this model, $80 \%$ of $\mathrm{CD}^{+} 6^{+}$cells in the bone marrow coexpressed myeloid markers such as CD33 or CD36. These cells lacked expression of conventional NK cell markers including NKG2D and NKp46 and were hypofunctional with regards to IFN- $\gamma$ production and cytotoxicity. However, $\mathrm{CD} 56^{+} \mathrm{CD} 36^{+} \mathrm{NK}$ cells sorted from the bone marrow of these mice and cultured in differentiation media containing stem cell factor (SCF), IL-15, and FLT-3 ligand exhibited maturation toward the conventional NK cell lineage as evidenced by loss of CD36 expression and acquisition of NKp46 and NKG2D. Similar observations were reported using $\mathrm{CD} 56^{+} \mathrm{CD} 36^{+}$cells isolated from human cord blood. Finally, the authors demonstrated that when purified $\mathrm{CD}^{+}{ }^{+} \mathrm{CD} 38^{+} \mathrm{CD} 123^{\text {low }} \mathrm{CD} 45 \mathrm{RA}^{+}$cells with a GMP phenotype were cultured in conditions supporting NK cell development, transient CD36 expression was observed followed by significant upregulation of CD56 (53).

It could be argued that NK cell development from myeloid progenitors is an artifact of the culture systems used and that it does not occur in vivo. Indeed, further studies need to be done in vivo to substantiate in vitro results. Nonetheless, given the plasticity of hematopoiesis described above, we believe that it's likely that some fraction of lineage-committed NK cells in humans derive from myeloid precursors. This notion is supported by other studies showing that under certain circumstances NK cells can share properties with DCs, such as MHC class II upregulation and antigen-presentation (54, 55). Conversely, there are conditions under which DCs acquire cytotoxicity characteristic of NK cells (56).

While much of the above discussion has highlighted hematopoietic plasticity and the multi-lineage potential of progenitor cells, results from a recent study by Dunbar and colleagues utilizing autologous transplantation of rhesus macaques with barcode-labeled $\mathrm{CD}_{3}{ }^{+}$cells suggest that the NK cell lineage is ontologically distinct. This contention was based on analysis of peripheral blood from macaques between 3- and 6.5-months post-transplant. Within this window, many shared clones were contributing to the granulocyte, monocyte, $\mathrm{T}$ cell and B cell lineages, while the clonal composition of NK cells was distinct. Additionally, distinct clonal patterns were observed for the more abundant $\mathrm{CD} 16^{+} \mathrm{CD} 56^{-} \mathrm{NK}$ cell subset compared to the less abundant $\mathrm{CD}_{16}{ }^{-} \mathrm{CD} 56^{+} \mathrm{NK}$ cell subset (57).

In a follow up study, the same group reported on NK cell reconstitution from the same rhesus macaques out to 4 years post-transplant. In this subsequent analysis, the differences in clonal contributions to the $\mathrm{CD} 16^{+} \mathrm{CD} 56^{-}$and $\mathrm{CD} 16^{-} \mathrm{CD} 56^{+}$ NK cell populations were still evident, and the $\mathrm{CD} 56^{-} \mathrm{CD} 16^{+}$ NK cell subset exhibited low clonal diversity. Despite technical challenges related to limited reagents to phenotype macaque NK cells, the authors also showed that reconstituted NK cells segregated by expression of KIR also exhibited clonal segregation. Furthermore, these clonal patterns were maintained after short term in vivo depletion with an anti-CD16 antibody. This finding suggests persistence and self-renewal of oligoclonal NK cell populations (58). If it can be assumed that (a) reconstitution of hematopoiesis after adoptive transfer of transduced CD34 ${ }^{+}$ progenitors accurately recapitulates NK cell ontogeny, (b) macaque and human $\mathrm{NK}$ cell development are reasonably equivalent, and (c) macaque $\mathrm{CD} 16^{+} \mathrm{CD} 56^{-}$and $\mathrm{CD} 16^{-} \mathrm{CD} 56^{+}$ $\mathrm{NK}$ cells are analogous to $\mathrm{CD} 56^{\mathrm{dim}}$ and $\mathrm{CD} 56^{\text {bright }} \mathrm{NK}$ cells, the results from this study suggest that CD56 bright $\mathrm{NK}$ cells and CD56 $6^{\mathrm{dim}} \mathrm{NK}$ cells are distinct lineages. This has obvious implications for the current model of human NK cell development where CD56 bright $\mathrm{NK}$ cells are assumed to be precursors of CD56 $6^{\mathrm{dim}} \mathrm{NK}$ cells. While the debate over whether CD56 bright $\mathrm{NK}$ cells are precursors of CD56 ${ }^{\mathrm{dim}} \mathrm{NK}$ cells or an independent lineage may seem somewhat trivial, it has important implications for generating NK cells for immunotherapy. It is possible that current culture systems which predominantly generate cells with a CD56 ${ }^{\text {bright }}$ phenotype favor the expansion/differentiation of a particular subset of precursor clones at the expense of other clones that differentiate into CD56 ${ }^{\text {dim }}$ NK cells.

\section{CONSIDERATIONS OF NK CELL DEVELOPMENT IN RELATION TO ILCS}

In recent years, much knowledge has been gained by studying NK cell development in parallel with the closely related ILCs and lymphoid tissue inducers (LTi). In one report describing committed ILC precursors, the immune systems

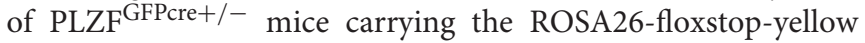
fluorescent protein fate (YFP)-mapping allele were analyzed in detail. GFP marked cells actively expressing promyelocytic leukemia zinc finger (PLZF), and YFP marked cells that had previously expressed PLZF at some point during their development. PLZF is a transcription factor that plays an important role in the effector differentiation of NKT cells (59, 60). Hematopoietic reconstitution experiments using progenitor cells from PLZF ${ }^{\mathrm{GFP} P r e+/-}$ mice demonstrated that the vast majority of NKT cells expressed YFP, whereas CLPs, B cells, and T cells were unlabeled. ILC1, ILC2, and ILC3 cells were YFP-labeled to varying extents. Interestingly, non-recirculating $\mathrm{DX}^{-} \mathrm{CD} 49 \mathrm{a}^{+} \mathrm{CD} 3 \varepsilon^{-} \mathrm{NK} 1.1^{+} \mathrm{NK}$ cells in the liver were heavily labeled, whereas classical recirculating $\mathrm{DX}^{+} \mathrm{CD} 49 \mathrm{a}^{-} \mathrm{NK}$ cells were mostly negative. In a search for the PLZF-expressing ILC precursor, the authors identified a rare subset of PLZFigh cells in fetal liver and adult bone marrow with a $\mathrm{Lin}^{-} \mathrm{IL}-$ $7 \mathrm{R} \alpha^{+}{ }^{+} \mathrm{Kit}^{+} \alpha 4 \beta 7^{\text {high }}$ phenotype that demonstrated ILC1, ILC2, and ILC3 potential at the clonal level. This potential excluded classical LTi and NK cells, but included non-recirculating DX5 ${ }^{-} \mathrm{CD} 49 \mathrm{a}^{+} \mathrm{CD} 3 \varepsilon^{-} \mathrm{NK} 1.1^{+} \mathrm{NK}$ cells. The results of this study suggest that liver-resident NK cells share a common progenitor with ILCs and that a distinct $\mathrm{PLZF}^{-}$progenitor gives rise to 
circulating NK cells (61). Whether PLZF expression is associated with the divergence of canonical NK cells and ILCs in humans has not yet been determined, and there may be important differences in PLZF expression patterns between species that limit the application of knowledge gained from these mouse experiments to human biology. In contrast to mice, recirculating canonical NK cells in humans are $\mathrm{PLZF}^{+}$, and PLZF downregulation through promoter DNA methylation is a hallmark of adaptive NK cells that arise in response to human cytomegalovirus (HCMV) (62).

Mice with an inhibitor of DNA binding 2 (Id2) reporter allele $\left(I d 2^{\mathrm{Gfp} /+}\right)$ have also been employed to track ILC progenitors (63). Id2 is a transcriptional regulator and inhibitor of $\mathrm{E}$ proteins (64). Genetic deletion of $I d 2$ in mice abrogates the development of all ILC lineages, including NK cells $(65,66)$. In $I d 2^{\mathrm{Gfp} /+}$-reporter mice, a $\mathrm{Lin}^{-} \mathrm{Id} 2^{+} \mathrm{IL}-7 \mathrm{R} \alpha^{+} \mathrm{CD} 25^{-} \alpha_{4} \beta_{7}^{+}$ cell population representing a common progenitor to the ILC1, ILC2, and ILC3 lineages was identified. This progenitor population was termed the common progenitor to all helperlike ILCs (CHILP). CHILP cells did not give rise to conventional NK cells in adoptive transfer experiments, indicating early divergence of the ILC and NK cell lineages (63). However, this interpretation has been recently challenged by DiSanto and colleagues who studied ILC and NK cell development using Id $2^{\mathrm{RFP}}$-reporter mice. The genomes of these mice contain an internal ribosome entry site monomeric red fluorescent protein (IRES-mRFP) cassette within exon 2 of the Id 2 gene. In these mice, RFP was highly expressed in all ILC subsets and in splenic and liver NK cells (67). In the current model of ILC development, $\operatorname{Lin}^{-} \mathrm{CD}_{117}{ }^{+} \mathrm{CD} 135^{-} \alpha_{4} \beta_{7}^{+} \mathrm{CD} 25^{-}$ ILC progenitors (ILCP) are considered the earliest precursor population giving rise to ILCs downstream of CLPs $(68,69)$. Analyses of immune cell reconstitution 5 weeks after adoptive transfer of bone marrow-derived Id $2^{\text {RFP }}$ ILCPs into sub-lethally irradiated immunodeficient mice showed that all ILC subsets as well as conventional NK cells were present in these mice. Additionally, when Id $2^{\text {RFP }}$ ILCPs were sorted and cultured on stroma with cytokines, single-cell cultures gave rise to both single and mixed colonies of ILC1s, ILC2s, ILC3s, and NK cells. To assess PLZF as a distinguishing factor of ILC progenitors, Id 2 RFP mice were crossed with $Z$ btb $16^{\text {GFPcre }}$ mice to generate doublereporter mice. $Z b t b 16$ is the gene encoding PLZF. $I d 2^{+} Z b t b 16^{-}$ and $I d 2^{+} Z b t b 16^{+}$ILCPs were purified from double-reporter mice and adoptively transferred into immunodeficient mice. Both populations gave rise exclusively to ILC subsets and NK cells with no detection of B cells, T cells or myeloid cells. Sorted $I d 2^{+} Z b t b 16^{+}$ILCPs could also give rise to all ILC subsets as well as NK cells in single-cell cultures. Results from these experiments performed with a more sensitive reporter system suggest that conventional NK cells and ILCs are derived from a common early precursor and that neither Id 2 nor PLZF distinguishes progenitors with differing lineage potential (67).

Not surprisingly, human ILC development is less wellcharacterized. A lineage-committed $\mathrm{CD}_{3}{ }^{+}$ILC3 precursor expressing the transcription factor ROR $\gamma t$ has been found in tonsil and intestinal lamina propria tissues but not in the peripheral blood, bone marrow or thymus (70). Freud and colleagues also identified a $\mathrm{Lin}^{-} \mathrm{CD} 34^{+} \mathrm{CD} 45 \mathrm{RA}^{+} \mathrm{CD} 117^{+} \mathrm{IL}-$ $1 \mathrm{R} 1^{+} \mathrm{ROR} \gamma \mathrm{t}^{+}$progenitor population that expressed ID2 and could differentiate into all ILC types, including conventional CD56 ${ }^{\text {bright }} \mathrm{NK}$ cells, in vitro. This progenitor was found in several different secondary lymphoid tissues (SLT) but not in hematopoietic tissues or thymus. Intriguingly, RORC1 and $R O R C 2$ (encoding ROR $\gamma$ ) transcripts were present in all mature ILC subsets and CD56 ${ }^{\text {bright }} \mathrm{NK}$ cells but not CD56 ${ }^{\text {dim }} \mathrm{NK}$ cells (71). This finding contrasts with fate-mapping studies in mice where $\operatorname{ROR} \gamma \mathrm{t}$ expression was found to be restricted to ILCs, and a ROR $\gamma \mathrm{t}^{+}$progenitor gave rise to subsets of ILCs but not NK cells $(72,73)$. The observation of RORC2 expression in CD56 ${ }^{\text {bright }}$ but not CD56 ${ }^{\text {dim }} \mathrm{NK}$ cells raises questions about the developmental relationship between these two subsets. It's possible that RORC2 expression is downregulated during the presumed developmental transition of CD56 ${ }^{\text {bright }} \mathrm{NK}$ cells into CD56 ${ }^{\mathrm{dim}}$ NK cells. Alternatively, RORC2 expression could be a lineage-defining factor that marks two distinct lineages (71).

While the two studies referenced above describe ILCs located in SLT, a recent report has extensively characterized human ILCPs that circulate in peripheral blood. These cells are found at a low frequency in blood and are $\mathrm{CD}_{4}{ }^{+} \mathrm{CD}^{-}{ }^{-} \mathrm{CD} 56{ }^{-} \mathrm{CD} 25^{+} \mathrm{CD} 127^{+} \mathrm{CD} 117^{+} \mathrm{IL} 1 \mathrm{R} 1{ }^{+} \mathrm{CD} 69^{-}$.

Analysis of progeny from single ILCP cell cultures showed that all ILC subsets as well as NK cells developed from ILCPs. ILCPs as defined in this study represented a heterogeneous population comprised of unipotent and multipotent progenitors, and some ILCPs exhibited the potential to generate both NK cells and ILCs at the single-cell level. In addition to peripheral blood, human ILCPs were identified in cord blood, SLT, fetal liver, and adult lung. Results from this work support the idea that circulating ILCPs can seed various tissues, and that environmental factors within the tissue can "instruct" further differentiation toward the ILC1, ILC2, ILC2, and NK lineages. Some of this instruction is likely given by the presence or absence of Notch ligands and the cytokine milieu (74). Collectively, these studies provide strong evidence that a precursor population exists in humans that has the potential to differentiate into ILCs and conventional NK cells. To what extent the total NK cell pool in humans is derived from an ILC/NK-restricted precursor is unknown and is a challenging question to address. It is possible that many tissue-restricted NK cell populations could arise from an ILC/NK-restricted precursor, while circulating peripheral blood NK cells arise from other CLP, CMP, or GMP populations. Because fate-mapping experiments cannot be carried out in humans for obvious ethical reasons, the continued refinement of humanized mouse models for analysis of human NK cell development might be the best approach for advancing our understanding.

\section{ADAPTIVE NK CELL DEVELOPMENT}

Over the past decade there has been considerable interest in the concept of NK cell memory. The idea that NK cells may possess attributes of immunological memory began with the discovery that mouse cytomegalovirus (MCMV) encodes an MHC-like protein (m157) that engages the activating receptor 
Ly49H on NK cells. This interaction was shown to be important for host protection against the virus $(75,76)$. Further analysis of the $\mathrm{Ly}_{49 \mathrm{H}}{ }^{+} \mathrm{NK}$ cell population in MCMV-infected mice revealed that these cells expanded robustly in the liver and spleen after infection. Following a contraction phase, the remaining Ly49H ${ }^{+}$cells remained in lymphoid and non-lymphoid organs for several months. Adoptive transfer experiments showed that these "memory" cells could undergo secondary expansion in response to viral challenge and conferred protective immunity (77). An analogous population of NK cells expressing the activating receptor NKG2C expands specifically in response to HCMV (78). While the Ly49H/m157 interaction is crucial for host protection against the virus, the same is not true for the NKG2C/HLA-E interaction. Approximately $4 \%$ of humans carry a homozygous deletion of KLRC2, the gene that encodes NKG2C. Because of built-in redundancy in the human response to HCMV, NK cells from $\mathrm{NKG}_{2} \mathrm{C}^{-/-}$individuals can still mount a response against the virus through other activating receptors $(78,79)$. This redundancy is reflected in the epigenetically regulated diversification of NK cell signaling and function that has been reported in HCMV seropositive individuals $(62,80)$. Another more general form of NK cell memory for haptens or viruses has also been described in mice. These NK cells are hepatic and express the chemokine receptor CXCR6 (81). This work has been extended to humans where it has been shown that a population of NK cells expressing tissue residency markers (CD69, CD62L, CXCR6) exhibit recall responses to varicella-zoster virus (VZV) and appear to be very long lived (82).

Little is known regarding the developmental origin or adaptive or memory NK cells. There is circumstantial evidence to suggest that the liver may be a site for NK cell memory acquisition. Two recent studies have characterized liver-resident NK cells from biopsied human tissue. These cells express the liver-specific adhesion molecules CXCR6 and CD49a. High frequencies of these cells also express NKG2C and $\operatorname{KIR}(83,84)$. It is possible that the liver is the primary extramedullary site for the development of adaptive NK cells. These cells could then traffic to sites of infection, expand upon activation and traffic through peripheral blood.

The developmental path from $\mathrm{CD}_{3}{ }^{+}$hematopoietic progenitor cell to adaptive NK cell has not yet been elucidated. It may be that the same lineage-restricted
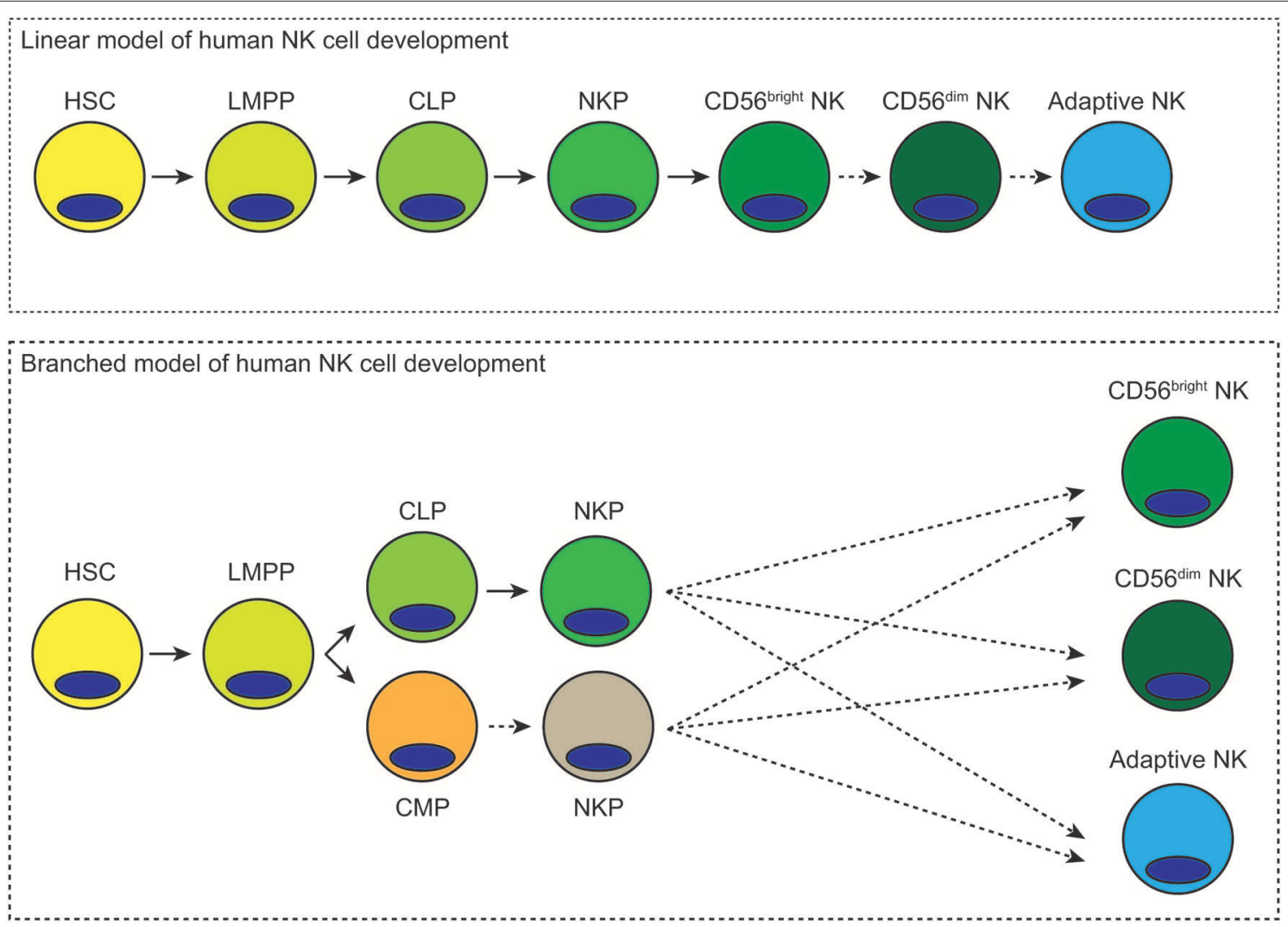

FIGURE 1 | Possible linear and branched models of human NK cell development. In the linear model of human NK cell development, hematopoietic stem cells differentiate into lymphoid-primed multipotential progenitors, which then become common lymphoid progenitors. Lineage commitment occurs at the NK precursor stage. These cells then mature first into CD56 bright NK cells and then CD56 dim NK cells. Differentiation into adaptive NK cells could subsequently occur in response to viral infection. In the branched model of human NK cell development, hematopoietic stem cells differentiate into lymphoid-primed multipotent progenitors, which then differentiate toward common lymphoid or myeloid progenitors. Either of these progenitors could give rise to NK cell progenitors. These NK cell progenitors could then differentiate into CD56 bright, CD56 ${ }^{\text {dim }}$, or adaptive NK cells. Dashed arrows represent hypothetical routes of development/differentiation. 
$\mathrm{Lin}^{-} \mathrm{CD} 34^{+} \mathrm{CD}_{3} 8^{+} \mathrm{CD} 123^{-} \mathrm{CD}_{45 \mathrm{RA}^{+} \mathrm{CD}}{ }^{+} \mathrm{CD} 10^{+} \mathrm{CD} 127^{-}$ NK cell precursor that has previous been described (33) can differentiate into adaptive NK cells under supportive conditions. Alternatively, there could exist a unique precursor cell that gives rise to an adaptive NK cell lineage. New experimental systems and approaches will likely be needed to understand the ontological relationship between adaptive and canonical NK cells. Currently, there are no studies that have reported on the ability to take canonical NK cells from HCMV seronegative donors and induce and adaptive NK cell state ex vivo.

\section{DISCUSSION}

Our understanding of hematopoiesis in general and NK cell development in particular has advanced considerably over the past several decades. There is now increased awareness of the plasticity of hematopoietic progenitor cells and their capacity for differentiating toward multiple lineages. One major unresolved question is whether human NK cells arise from a distinct set of clonal precursors or whether they arise from multi-potent progenitors that also split off into the T cell, B cell or myeloid lineages. If $\mathrm{NK}$ cells have a particularly unique ontogeny, at what stage of hematopoiesis do they diverge? Another major question that remains to be resolved is whether CD56 bright $\mathrm{NK}$ cells represent a distinct lineage or whether they are precursors of CD56 ${ }^{\text {dim }} \mathrm{NK}$ cells. A third major question is the developmental origin of adaptive NK cells and whether they represent a lineage distinct from canonical NK cells. To what degree is NK cell development a linear path from hematopoietic stem cell to terminally mature NK cell, and to what degree is it a branched process where different progenitor cell populations give rise to distinct NK cell lineages (Figure 1)? More in depth investigation and the development of new approaches and technologies should shed more light on these difficult questions and provide more

\section{REFERENCES}

1. Jacobson LO, Simmons EL, Marks EK, Eldredge JH. Recovery from radiation injury. Science. (1951) 113:510-11. doi: 10.1126/science.113.2940.510

2. Till JE, McCulloch EA. A direct measurement of the radiation sensitivity of normal mouse bone marrow cells. Radiat Res. (1961) 14:213-22. doi: $10.2307 / 3570892$

3. Becker AJ, McCulloch EA, Till JE. Cytological demonstration of the clonal nature of spleen colonies derived from transplanted mouse marrow cells. Nature. (1963) 197:452-54. doi: 10.1038/197452a0

4. Spangrude GJ, Heimfeld S, Weissman IL. Purification and characterization of mouse hematopoietic stem cells. Science. (1988) 241:58-62. doi: $10.1126 /$ science. 2898810

5. Doulatov S, Notta F, Eppert K, Nguyen LT, Ohashi PS, Dick JE. Revised map of the human progenitor hierarchy shows the origin of macrophages and dendritic cells in early lymphoid development. Nat Immunol. (2010) 11:585-93. doi: 10.1038/ni.1889

6. Lu M, Kawamoto $\mathrm{H}$, Katsube $\mathrm{Y}$, Ikawa $\mathrm{T}$, Katsura $\mathrm{Y}$. The common myelolymphoid progenitor: a key intermediate stage in hemopoiesis generating T and B cells. J Immunol. (2002) 169:3519-25. doi: 10.4049/jimmunol.169.7.3519

7. Bell JJ, Bhandoola A. The earliest thymic progenitors for $\mathrm{T}$ cells possess myeloid potential. Nature. (2008) 452:764-7. doi: 10.1038/nature06840 definitive answers. It is also important to keep in mind the myriad differences between mice and humans with regards to hematopoiesis and immune cell development.

While these questions are interesting from an academic perspective, advancements in our understanding of human NK cell development will be critical for the development of new immunotherapies. One major challenge is how to successfully treat patients with solid tumors with an NK cell therapy. We know that NK cells exist within peripheral tissues where tumors can arise and can infiltrate the tumor microenvironment. However, we do not know the precise developmental pathway these NK cells take, which precursors they differentiate from or what environmental cues instruct their maturation. With this knowledge, we could potentially guide the differentiation of either a subset of $\mathrm{CD} 34^{+}$progenitors or induced pluripotent stem cells (iPSCs) in vitro to generate NK cells for adoptive immunotherapy that will home to specific tissues and persist. Similarly, we know that certain subsets of NK cells respond specifically to HCMV, VSV, and EBV infections. There is potential to develop an NK cell-based immunotherapy to treat patients who have complications from these infections. For this approach to become a reality, we need a better understanding of the developmental origins of these virusspecific NK cell subsets.

\section{AUTHOR CONTRIBUTIONS}

FC, BG, and JM wrote the manuscript.

\section{FUNDING}

This work was supported by NIH grants K99/R00 HL123638 (to FC), P01 CA111412 (to JM), P01 CA65493 (to JM), and R35 CA197292 (to JM).
8. Wada H, Masuda K, Satoh R, Kakugawa K, Ikawa T, Katsura Y, et al. Adult T-cell progenitors retain myeloid potential. Nature. (2008) 452:768-2. doi: 10.1038/nature06839

9. Balciunaite G, Ceredig R, Massa S, Rolink AG. A B220+ CD177+_ CD19hematopoietic progenitor with potent lymphoid and myeloid developmental potential. Eur J Immunol. (2005) 35:2019-30. doi: 10.1002/eji.200526318

10. Montecino-Rodriguez E, Leathers H, Dorshkind K. Biopotential Bmacrophage progenitors are present in adult bone marrow. Nat Immunol. (2001) 2:83-8. doi: 10.1038/83210

11. Adofsson J, Mansson R, Buza-Vidas N, Hultquist A, Liuba K, Jensen CT, et al. Identification of Flt3+ lympho-myeloid stem cells lacking erythromegakaryocytic potential a revised road map for adult blood lineage commitment. Cell. (2005) 121:295-306. doi: 10.1016/j.cell.2005.02.013

12. Arinobu Y, Mizuno S, Chong Y, Shigematsu H, Iwasaki H, Graf T, et al. Reciprocal activation of GATA-1 and PU.1 marks initial specification of hematopoietic stem cells into myeloerythroid and myelolymphoid lineages. Cell Stem Cell. (2007) 1:416-27. doi: 10.1016/j.stem.2007.07.004

13. Lai AY, Kondo M. Asymmetrical lymphoid and myeloid lineage commitment in multipotent hematopoietic progenitors. J Exp Med. (2006) 203:1867-73. doi: $10.1084 /$ jem.20060697

14. Yoshida T, Ng SY, Zuniga-Pflucker JC, Georgopoulos K. Early hematopoietic lineage restrictions directed by Ikaros. Nat Immunol. (2006) 7:382-91. doi: $10.1038 /$ ni1314 
15. Akashi K, Traver D, Miyamoto T, Weissman IL. A clonogenic common myeloid progenitor that gives rise to all myeloid lineages. Nature. (2000) 404:193-7. doi: 10.1038/35004599

16. Pronk CJ, Rossi DJ, Mansson R, Attema JL, Norddahl GL, Chan CK, et al. Elucidation of the phenotypic, functional, and molecular topography of a myeloerythroid progenitor cell hierarchy. Cell Stem Cell. (2007) 1:428-42. doi: 10.1016/j.stem.2007.07.005

17. Hackett J Jr, Bennett M, Kumar V. Origin and differentiation of natural killer cells. I. Characteristics of a transplantable NK cell precursor. I Immunol. (1985) 134:3731-8.

18. Phillips JH, Hori T, Nagler A, Bhat N, Spits H, Lanier LL. Ontogeny of human natural killer (NK) cells: fetal NK cells mediate cytolytic function and express cytoplasmic CD3 epsilon, delta proteins. J Exp Med. (1992) 175:1055-66. doi: $10.1084 /$ jem.175.4.1055

19. Rodewald HR, Moingeon P, Lucich JL, Dosiou C, Lopez P, Reinherz EL. A population of early fetal thymocytes expressing Fc gamma RII/III contains precursors of T lymphocytes and natural killer cells. Cell. (1992) 69:139-50. doi: 10.1016/0092-8674(92)90125-V

20. Carlyle JR, Michie AM, Furlonger C, Nakano T, Lenardo MH, Paige $\mathrm{CJ}$, et al. Identification of a novel developmental stage marking lineage commitment of progenitor thymocytes. J Exp Med. (1997) 186:173-82. doi: 10.1084/jem.186.2.173

21. Bezman NA, Kim CC, Sun JC, Min-Oo G, Hendricks DW, Kamimura Y, et al. Molecular definition of the identity and activation of natural killer cells. Nat Immunol. (2012) 13:1000-9. doi: 10.1038/ni.2395

22. Wakabayashi Y, Watanabe H, Inoue J, Sakata J, Mishima Y, Hitomi J, et al. Bcl11b is required for differentiation and survival of alphabeta T lymphocytes. Nat Immunol. (2003) 4:533-9. doi: 10.1038/ni927

23. Ikawa T, Hirose S, Masuda K, Kakugawa K, Satoh R, Shibano-Satoh A, et al. An essential developmental checkpoint for the production of the T cell lineage. Science. (2010) 329:93-6. doi: 10.1126/science.1188995

24. Li L, Leid M, Rothenberg EV. An early T cell lineage commitment checkpoint dependent on the transcription factor Bcl11b. Science. (2010) 329:89-93. doi: 10.1126/science.1188989

25. Li P, Burke S, Wang J, Chen X, Ortiz M, Lee SC, et al. Reprogramming of T cells to natural killer-like cells upon Bcl11b deletion. Science. (2010) 329:85-9. doi: 10.1126/science.1188063

26. Punwani D, Zhang Y, Yu J, Cowan MJ, Rana S, Kwan A, et al. Multisystem abnormalities in severe combined immunodeficiency with mutant BCL11B. N Engl J Med. (2016) 375:2165-76. doi: 10.1056/NEJMoa1509164

27. Alhaj Hussen K, Vu Manh TP, Guimiot F, Nelson E, Chabaane E, Delord $\mathrm{M}$, et al. Molecular and functional characterization of lymphoid progenitor subsets reveals a bipartite architecture of human lymphopoiesis. Immunity. (2017) 47:680-96. doi: 10.1016/j.immuni.2017.09.009

28. Galy A, Travis M, Cen D, Chen B. Human T, B, natural killer, and dendritic cells arise from a common bone marrow progenitor cell subset. Immunity. (1995) 3:459-73. doi: 10.1016/1074-7613(95)90175-2

29. Miller JS, McCullar V, Punzel M, Lemischka IR, Moore KA. Single adult human CD34(+)/Lin-/CD38(-) progenitors give rise to natural killer cells, B-lineage cells, dendritic cells, and myeloid cells. Blood. (1999) 93:96-106.

30. Haddad R, Guardiola P, Izac B, Thibault C, Radich J, Delezoide AL, et al. Molecular characterization of early human T/NK and B-lymphoid progenitor cells in umbilical cord blood. Blood. (2004) 104:3918-26. doi: 10.1182/blood-2004-05-1845

31. Miller JS, Alley KA, McGlave P. Differentiation of natural killer (NK) cells from human primitive marrow progenitors in a stroma-based long-term culture system: identification of a CD34+CD7+ NK progenitor. Blood. (1994) 83:2594-601.

32. Hao QL, Zhu J, Price MA, Payne KJ, Barsky LW, Crooks GM. Identification of a novel, human multilymphoid progenitor in cord blood. Blood. (2001) 97:3683-90. doi: 10.1182/blood.V97.12.3683

33. Renoux VM, Zriwil A, Peitzsch C, Michaelsson J, Friberg D, Soneji $\mathrm{S}$, et al. Identification of a human natural killer cell lineage-restricted progenitor in fetal and adult tissues. Immunity. (2015) 43:394-407. doi: 10.1016/j.immuni.2015.07.011

34. Bozzano F, Marras F, Ascierto ML, Cantoni C, Cenderello G, Dentone C, et al. "Emergency exit" of bone-marrow-resident CD34(+)DNAM-1(bright)CXCR4(+)-committed lymphoid precursors during chronic infection and inflammation. Nat Commun. (2015) 6:8109. doi: $10.1038 /$ ncomms9109

35. Mrozek E, Anderson P, Caligiuri MA. Role of interleukin-15 in the development of human CD56+ natural killer cells from CD34+ hematopoietic progenitor cells. Blood. (1996) 87:2632-40.

36. Jaleco AC, Blom B, Res P, Weijer K, Lanier LL, Phillips JH, et al. Fetal liver contains committed NK progenitors, but is not a site for development of CD34+ cells into T cells. J Immunol. (1997) 159:694-702.

37. Sanchez MJ, Spits H, Lanier LL, Phillips JH. Human natural killer cell committed thymocytes and their relation to the T cell lineage. J Exp Med. (1993) 178:1857-66. doi: 10.1084/jem.178.6.1857

38. Freud AG, Becknell B, Roychowdhury S, Mao HC, Ferketich AK, Nuovo $\mathrm{GJ}$, et al. A human $\mathrm{CD} 34(+)$ subset resides in lymph nodes and differentiates into CD56bright natural killer cells. Immunity. (2005) 22:295304. doi: 10.1016/j.immuni.2005.01.013

39. Yu J, Freud AG, Caligiuri MA. Location and cellular stages of natural killer cell development. Trends Immunol. (2013) 34:573-82. doi: 10.1016/j.it.2013.07.005

40. Dulphy N, Haas P, Busson M, Belhadj S, Peffault de Latour R, Robin M. An unusual CD56(bright) CD16(low) NK cell subset dominates the early posttransplant period following HLA-matched hematopoietic stem cell transplantation. J Immunol. (2008) 181:2227-37. doi: 10.4049/jimmunol.181.3.2227

41. Yu J, Mao HC, Wei M, Hughes T, Zhang J, Park IK, et al. CD94 surface density identifies a functional intermediary between the CD56bright and CD56dim human NK-cell subsets. Blood. (2010) 115:274-81. doi: 10.1182/blood-2009-04-215491

42. Yu J, Wei M, Mao H, Zhang J, Hughes T, Mitsui T, et al. CD94 defines phenotypically and functionally distinct mouse NK cell subsets. J Immunol. (2009) 183:4968-74. doi: 10.4049/jimmunol.0900907

43. Chan A, Hong DL, Atzberger A, Kollnberger S, Filer AD, Buckley CD, et al. CD56bright human NK cells differentiate into CD56dim cells: role of contact with peripheral fibroblasts. J Immunol. (2007) 179:89-94. doi: 10.4049/jimmunol.179.1.89

44. Romagnani C, Juelke K, Falco M, Morandi B, D’Agostino A, Costa R, et al. CD56brightCD16- killer Ig-like receptor- NK cells display longer telomers and acquire features of CD56dim NK cells upon activation. J Immunol. (2007) 178:4947-55. doi: 10.4049/jimmunol.178.8.4947

45. Bjorkstrom NK, Riese P, Heuts F, Andersson S, Fauriat C, Ivarsson MA, et al. Expression patterns of NKG2A, KIR, and CD57 define a process of CD56dim NK-cell differentiation uncoupled from NK-cell education. Blood. (2010) 116:3853-64. doi: 10.1182/blood-2010-04-281675

46. Lopez-Verges S, Milush JM, Pandey S, York VA, Arakawa-Hoyt J, Pircher $\mathrm{H}$, et al. CD57 defines a functionally distinct population of mature NK cells in the human CD56dimCD16+ NK-cell subset. Blood. (2010) 116:3865-74. doi: 10.1182/blood-2010-04-282301

47. Miller JS, McCullar V. Human natural killer cells with polyclonal lectin and immunoglobulinlike receptors develop from single hematopoietic stem cells with preferential expression of NKG2A and KIR2DL2/L3/S2. Blood. (2001) 98:705-13. doi: 10.1182/blood.V98.3.705

48. Grzywacz B, Kataria N, Sikora M, Oostendorp RA, Dzierzak EA, Blazar $\mathrm{BR}$, et al. Coordinated acquisition of inhibitory and activating receptors and functional properties by developing human natural killer cells. Blood. (2006) 108:3824-33. doi: 10.1182/blood-2006-04-020198

49. Horowitz A, Stauss-Albee DM, Leipold M, Kubo J, Nemat-Gorgani N, Dogan OC, et al. Genetic and environmental determinants of human NK cell diversity revealed by mass cytometry. Sci Trans Med. (2013) 5:208ra145. doi: 10.1126/scitranslmed.3006702

50. Grzywacz B, Kataria N, Kataria N, Blazar BR, Miller JS, Verneris MR. Natural killer-cell differentiation by myeloid progenitors. Blood. (2011) 117:3548-58. doi: 10.1182/blood-2010-04-281394

51. Roussel MF, Cleveland JL, Shurtleff SA, Sherr CJ. Myc rescue of a mutant CSF-1 receptor impaired in mitogenic signaling. Nature. (1991) 353:361-63. doi: $10.1038 / 353361 \mathrm{a} 0$

52. Cichocki F, Hanson RJ, Lenvik T, Pitt M, McCullar V, Li H, et al. The transcription factor $\mathrm{c}-\mathrm{Myc}$ enhances KIR gene transcription through direct binding to an upstream distal promoter element. Blood. (2009) 113:3245-53. doi: 10.1182/blood-2008-07-166389 
53. Chen Q, Ye W, Jian Tan W, Mei Yong KL, Liu M, Qi Tan S, et al. Delineation of natural killer cell differentiation from myeloid progenitors in human. Sci Rep. (2015) 5:15118. doi: 10.1038/srep15118

54. Phillips JH, Le AM, Lanier LL. Natural killer cells activated in a human mixed lymphocyte response culture identified by expression of Leu-11 and class II histocompatibility antigens. J Exp Med. (1984) 159:993-1008. doi: 10.1084/jem.159.4.993

55. Costa-Garcia M, Ataya M, Moraru M, Vilches C, Lopez-Botet $M$, Muntasell A. Human cytomegalovirus antigen presentation by HLA$\mathrm{DR}+\mathrm{NKG} 2 \mathrm{C}+$ adaptive $\mathrm{NK}$ cells specifically activates polyfunctional effector memory CD4+ T lymphocytes. Front Immunol. (2019) 10:687. doi: 10.3389/fimmu.2019.00687

56. Stary G, Bangert C, Tauber M, Strohal R, Koop T, Stingl G. Tumoricidal activity of TLR7/8-activated inflammatory dendritic cells. J Exp Med. (2007) 204:1441-51. doi: 10.1084/jem.20070021

57. Wu C, Li B, Lu R, Koelle SJ, Yang Y, Jares A, et al. Clonal tracking of rhesus macaque hematopoiesis highlights a distinct lineage origin for natural killer cells. (2014) 14:486-99. doi: 10.1016/j.stem.2014.01.020

58. Wu C, Espinoza DA, Koelle SJ, Yang D, Truitt L, Schlums H, et al. Clonal expansion and compartmentalized maintenance of rhesus macaque NK cell subsets. Sci Immunol. (2018) 3:eaat9781. doi: 10.1126/sciimmunol.aat9781

59. Savage AK, Constantinides MG, Han J, Picard D, Martin E, Li B, et al. The transcription factor PLZF direct the effector program of the NKT cell lineage. Immunity. (2008) 29:391-403. doi: 10.1016/j.immuni.2008.07.011

60. Kovalovsky D, Uche OU, Eladad S, Hobbs RM, Yi W, Alonzo E, et al. The BTB-zinc finger transcriptional regulator PLZF controls the development of invariant natural killer T cell effector functions. Nat Immunol. (2008) 9:1055-64. doi: 10.1038/ni.1641

61. Constantinides MG, McDonald BD, Verhoef PA, Bendelac A. A committed precursor to innate lymphoid cells. Nature. (2014) 508:397-401. doi: 10.1038/nature13047

62. Schlums H, Cichocki F, Tesi B, Theorell, Beziat V, Holmes TD, et al. Cytomegalovirus infection drives adaptive epigenetic diversification of NK cells with altered signaling and effector function. Immunity. (2015) 42:443-56. doi: 10.1016/j.immuni.2015.02.008

63. Klose CSN, Flach M, Möhle L, Rogell L, Ebert K, Fabiunke C, et al. Differentiation of type 1 ILCs from a common progenitor to all helper-like innate lymphoid cell lineages. Cell. (2014) 157:340-56. doi: $10.1016 /$ j.cell.2014.03.030

64. Kee BL. E and ID proteins branch out. Nat Rev Immunol. (2009) 9:175-84. doi: $10.1038 /$ nri2507

65. Moro K, Yamada T, Tanabe M, Takeuchi T, Ikawa T, Kawamoto H, et al. Innate production of $\mathrm{T}(\mathrm{H}) 2$ cytokines by adipose tissue-associated c-Kit $(+) \mathrm{Sca}-1(+)$ lymphoid cells. Nature. (2010) 463:540-4. doi: 10.1038/nature08636

66. Yokota Y, Mansouri A, Mori S, Sugawara S, Adachi S, Nishikawa, et al. Development of peripheral lymphoid organs and natural killer cells depends on the helix-loop-helix inhibitor Id2. Nature. (1999) 397:702-6. doi: $10.1038 / 17812$

67. Xu W, Cherrier DE, Chea S, Vosshenrich C, Serafini N, Petit M, et al. An $\mathrm{Id} 2^{\mathrm{RFP}}$-reporter mouse redefines innate lymphoid cell precursor potentials. Immunity. (2019) 50:1054-68. doi: 10.1016/j.immuni.2019.02.022

68. Serafini N, Vosshenrich CA, Di Santo JP. Transcriptional regulation of innate lymphoid cell fate. Nat Rev Immunol. (2015) 15:415-28. doi: 10.1038/nri3855

69. Zook EC, Kee BL. Development of innate lymphoid cells. Nat Immunol. (2016) 17:775-82. doi: 10.1038/ni.3481

70. Montaldo E, Teixeira-Alves LG, Glatzer T, Durek P, Stervbo U, Hamann W, et al. Human ROR $\gamma \mathrm{t}(+) \mathrm{CD} 34(+)$ cells are lineage-specified progenitors of group 3 ROR $\gamma \mathrm{t}(+)$ innate lymphoid cells. Immunity. (2014) 41:988-1000. doi: 10.1016/j.immuni.2014.11.010

71. Scoville SD, Mundy-Bosse BL, Zhang MH, Chen L, Zhang X, Keller KA, et al. A progenitor cell expressing transcription factor ROR $\gamma \mathrm{t}$ generates all human innate lymphoid cell subsets. Immunity. (2016) 44:1140-50. doi: 10.1016/j.immuni.2016.04.007
72. Satoh-Takayama N, Lesjean-Pottier S, Vieira P, Sawa S, Eberl G, Vosshenrich CA, et al. IL-7 and IL-15 independently program the differentiation of intestinal CD3-NKp46+ cell subsets from Id2 precursors. J Exp Med. (2010) 207:273-80. doi: 10.1084/jem.20092029

73. Vonarbourg C, Mortha A, Hernandez PP, Kiss EA, Hoyler T, Flach $\mathrm{M}$, et al. Regulated expression of nuclear receptor ROR $\gamma \mathrm{t}$ confers distinct functional fates to NK cell receptor-expressing ROR $\gamma \mathrm{t}(+)$ innate lymphocytes. Immunity. (2010) 33:736-51. doi: 10.1016/j.immuni.2010. 10.017

74. Lim AI, Li Y, Lopez-Lastra S, Stadhouders R, Paul F, Casrouge A, et al. Systemic human ILC precursors provide a substrate for tissue ILC differentiation. Cell. (2017) 168:1086-1100. doi: 10.1016/j.cell.2017.02.021

75. Arase H, Mocarski ES, Campbell AE, Hill AB, Lanier LL. Direct recognition of cytomegalovirus by activating and inhibitory NK cell receptors. Science. (2002) 296:1323-6. doi: 10.1126/science.1070884

76. Smith HR, Heusel JW, Mehta IK, Kim S, Dorner BG, Naidenko $\mathrm{OV}$, et al. Recognition of a virus-encoded ligand by a natural killer cell activation receptor. Proc Natl Acad Sci USA. (2002) 99:8826-31. doi: 10.1073/pnas.092258599

77. Sun JC, Beilke JN, Lanier LL. Adaptive immune features of natural killer cells. Nature. (2009) 457:557-61. doi: 10.1038/nature07665

78. Guma M, Angulo A, Vilches C, Gomez-Lozano N, Malats N, LopezBotet M. Imprint of human cytomegalovirus infection on the NK cell receptor repertoire. Blood. (2004) 104:3664-71. doi: 10.1182/blood-2004-052058

79. Liu LL, Landskron J, Ask EH, Enqvist M, Sohlberg E, Traherne JA, et al. Critical role of CD2 co-stimulation in adaptive natural killer cell responses revealed in NKG2C-deficient humans. Cell Rep. (2016) 15:1088-99. doi: 10.1016/j.celrep.2016.04.005

80. Lee J, Zhang T, Hwang I, Kim A, Nitschke L, Kim M, et al. Epigenetic modification and antibody-dependent expansion of memory-like NK cells in human cytomegalovirus-infected individuals. Immunity. (2015) 42:431-42. doi: 10.1016/j.immuni.2015.02.013

81. Paust S, Gill HS, Wang BZ, Flynn MP, Moseman EA, Senman B, et al. Critical role for the chemokine receptor CXCR6 in NK cell-mediated antigenspecific memory of haptens and viruses. Nat Immunol. (2010) 11:1127-35. doi: 10.1038/ni.1953

82. Nikzad R, Angelo LS, Aviles-Padilla K, Le DT, Singh VK, Bimler L, et al. Human natural killer cells mediate adaptive immunity to viral antigens. Sci Immunol. (2019) 4:eaat8116. doi: 10.1126/sciimmunol.aat8116

83. Marquardt N, Beziat V, Nystrom S, Hengst J, Ivarsson MA, Kekalainen $\mathrm{E}$, et al. Cutting edge: identification and characterization of human intrahepatic CD49a+ NK cells. J Immunol. (2015) 194:2467-71. doi: 10.4049/jimmunol.1402756

84. Hydes T, Abuhilal M, Armstrong T, Primrose J, Takhar A, Khakoo S Natural killer cell maturation markers in the human liver and expansion of an NKG2C+KIR+ population. Lancet. (2015) 385(Suppl. 1):S45. doi: 10.1016/S0140-6736(15)60360-9

Conflict of Interest Statement: The authors declare that the research was conducted in the absence of any commercial or financial relationships that could be construed as a potential conflict of interest.

The reviewer SS and handling editor declared their shared affiliation at the time of review.

Copyright (c) 2019 Cichocki, Grzywacz and Miller. This is an open-access article distributed under the terms of the Creative Commons Attribution License (CC BY). The use, distribution or reproduction in other forums is permitted, provided the original author(s) and the copyright owner(s) are credited and that the original publication in this journal is cited, in accordance with accepted academic practice. No use, distribution or reproduction is permitted which does not comply with these terms. 